\title{
Intraoperative respira- tory complications in patients with upper respiratory tract infections
}

A retrospective survey of 3,585 patiens aged newborn to 20 years was performed to investigate the prevalence of intraoperative respiratory complications in patients with symptoms of upper respiratory tract infections (URIs). There were no significant differences in complication rates between asymptomatic patients (1.61 per 100) and those with symptoms (1.64 per 100); however, patients who were asymptomatic but had a recent history of an URI had a significantly higher complicalion rate $(5.31$ per $100 ; p<0.05)$ than the asymptomatic patients. There were no significant differences in intraoperative complications between patiens managed with and without tracheal intubarion, nor was there any association berween the type of anaesthetic agent used and the development of intraoperative respiratory complications. Resuits from the study suggest no increased risk of respiratory complications for patients presenting with uncomplicated URIs. However, patients who were asymptomatic but had a recent history of an URI showed a significanty increased risk for the development of intraopera. tive complications.

\section{Key words}

RESPIRATORY COMPLICATIONS; laryngospasm, bronchospasm; INFECrIONs: viral, upper respiratory; ANAESTHETICS: general; ANAESTHETIC TECHNIOUES: intubation

From the Department of Anesthesiology, University of Michigan Medical Center, Ann Arbor, Michigan 48109-0010. Address correspondence to Dr. Tait.

This work was supported in part by a grant from the Division of Rescarch Grants, National Institutes of Health (GM28911), Paul R. Knight, Principal Investigator.
Evidence describing the effects of general anaesthesia on the course of viral infections is particularly sparse. Clinical studies attempting to elucidate cause-effect relationships between the administration of anaesthesia and the development of perioperative complications in patients harbouring viral infections have for the most part been empirical in nature, whereas many animal studies have involved the use of anaesthetics which are no longer in use. ${ }^{1-4}$

Traditionally, for elective procedures, anaesthetists are taught to avoid anaesthetizing patients who harbour viral infections. This is particularly true of patients prescnting with infections of the upper respiratory tract (URIs). Such a training doctrine is the result of a belief among anaesthetists that respiratory tract infections may be exacerbated by general anaesthesia andior that the potential for perioperative complications is enhanced. As a result of this philosophy, most institutions have policies in which patients presenting at the time of their elective surgery with a respiratory tract infection are rescheduled until asymptomatic, a delay that is undoubtedly psychologically unsettling for the patient as well as being both inconvenient and costly to the patients, their relatives and physicians alike. Postponement of surgery is particularly common in paediatric practice where viral URIs are commonplace.

This retrospective study was designed in an attempt to evaluate the prevalence of respiratory complications in patients with URIs and to investigate the contribution of age, sex, amaesthesia time, intubation and type of anaesthesia on the development of these complications.

\section{Methods}

A retrospective analysis of consecutive malc and female patients between the ages of newborn to 20 years was performed for the period January, 1982, through Decenber, 1982. These patients underwent multiple surgical procedures involving nine different services at the University of Michigan C.S. Mott Children's Hospital.

Patients were classified as having an URI if it was so 
stated in the records or if any two of the following symptoms were recorded: sore or "scratchy" throat, sneezing, rhinorrhoea, congestion, malaise, cough, fever greater than $38.3^{\circ} \mathrm{C}$ or laryngitis. Based on these clinical criteria, the patients were divided into three groups. Group I $(n=$ 3,350 ) consisted of patients who were asymptomatic and had no recent history of an URI. Group II $(n=122)$ consisted of paticnts who fulfilled the URI criteria and Group III ( $n=133$ ) were patients asymptomatic at the time of surgery but who had a history of URI within the two weeks preceding surgery.

All information regarding patient demographics, presenting symptoms, and intraoperative complications were obtained from the anaesthesia records. Chart reviewers responsible for recording and coding intraoperative complications were blind to the patient's URI classification.

Comparison of the prevalence rates for respiratory complications was by chi square analysis. Analytical variables such as duration of anaesthesia and surgery were compared using analysis of variance.

\section{Results}

A total of 3,954 anaesthesia charts were reviewed, of which 3,585 were deemed suitable to study. Patients were excluded from the study for the following reasons: (1) age greater than the upper limit, (2) they did not receive a general anaesthetic, and (3) incomplete or unreadable charts. Exclusion criteria were similar for each group.

The three groups of patients were well matched with respect to age and sex. The mean $( \pm S D)$ ages were: Group I $5.65 \pm 5.26$ years, Group II $5.42 \pm 5.22$ years, and Group III $4.99 \pm 4.40$ years.

The most prevalent presenting respiratory symptoms were rhinorrhoea ( 47.5 per 100), nonproductive cough (35.3 per 100), and congestion (11.4 per 100). Of the total population, 1.65 per cent exhibited intraoperative respiratory complications. These complications included laryngospasm (1.26 per cent), bronchospasm ( 0.17 per cent), respiratory stridor $(0.08$ per cent), and breath holding ( 0.14 per cent). One intraoperative death was observed but was not associated with the presence or history of URI or the development of respiratory complications. The prevalence of intraoperative respiratory complications for Groups I and II was 1.61 (per 100) and 1.64 (per 100) respectively. The prevalence of these complications in Group III was 5.31 (per 100) which was statistically higher than Group $I(p<0.05)$ but nol Group II. The distribution of complications by type is described in Table 1 . It can be seen that laryngospasm was the most prevalent complication in each group. Respiratory complications were found to be more prevalent in the younger age groups (newborn to five years).
TABLE 1 Intraoperatjve complications by type; prevalence (per 100)

\begin{tabular}{lllll}
\hline Group & Laryngospasm & Bronchospasm & Siridor & $\begin{array}{l}\text { Breath } \\
\text { holding }\end{array}$ \\
\hline I & 78.4 & 7.8 & 5.9 & 7.8 \\
II & 50.0 & 0.0 & 0.0 & 50.0 \\
III & 66.7 & 33.3 & 0.0 & 0.0 \\
\hline
\end{tabular}

TABLE II Duration of anaesthesia and surgery

\begin{tabular}{lll}
\hline Group & $\begin{array}{l}\text { Anaesrhesia (min) } \\
\text { (mear } \pm S D)\end{array}$ & $\begin{array}{l}\text { Surgery (min) } \\
\text { (mean } \pm S D)\end{array}$ \\
\hline J & $92 \pm 56$ & $70 \pm 53$ \\
II & $81 \pm 37$ & $56 \pm 30$ \\
III & $73 \pm 9$ & $47 \pm 14$ \\
\hline
\end{tabular}

The mean ( \pm SD) age of children with respiratory complications in Group I was $4.27 \pm 4.93$ years compared to $4.25 \pm 3.47$ and $3.87 \pm 5.54$ years for Groups II and III respcctively. Intraoperative respiratory complications tended to be higher in males than females. For all groups, the ratio of males to females demonstrating complications was 2:1 compared to a total population ratio of $1.18: 1$. There were no differences between groups in terms of presenting physical status as determined by the American Society of Anesthesiologists physical status classification.

The duration of anaesthesia and surgery was not significantly different in each group (Table II). Interestingly, however, Group III which had the highest number of complications also had the shortest anaesthetic and surgical times. In addition, the types of surgery in each group were similar with the highest proportion of cases belonging to general surgery and otolaryngology.

The effect of tracheal intubation on the development of intraoperative complications in patients with URIs was also examined. Despite the fact that the majority of patients were intubatcd, respiratory complications were observed in only 1.8 per cent of this group compared to a complication rate of 1.6 per cent for non-intubated patients. The requirement for tracheal intubation was related to the nature of the surgical procedure. Only two patients required intubation as a result of intraoperative laryngospasm. Both these patients had been asymptomatic on presentation to surgery. In Group I, 64.7 per cent of the patients were intubated which compared with an intubation rate of 58.2 and 64.7 per cent for Groups II and III respectively.

Although the prevalence of respiratory complications in each individual group was small, no significant differences were observed between intubated and non-intubated patients. Similarly, no association between the type of 
TABLE UI Angesthęsia

\begin{tabular}{lll}
\hline Anaesthetic agent & \% Usage & \% Complications \\
\hline Halothane & $67.8(\mathrm{n}=2,429)$ & $1.9(\mathrm{n}=47)$ \\
Enflurane & $15.3(\mathrm{n}=549)$ & $1.5(\mathrm{n}=8)$ \\
Isoflurane & $3.8(\mathrm{n}=136)$ & $1.5(\mathrm{n}=2)$ \\
Other & $13.1(\mathrm{n}=47)$ & $1.1(\mathrm{n}=5)$ \\
\hline
\end{tabular}

anaesthecic and the development of respiratory complications was observed (Table III).

\section{Discussion}

This retrospective study suggests that there is no increase in intraoperative complications associated with patients presenting with uncomplicated upper respiratory tract infections. However, patients who were asymptomatic at the time of surgery, but had a history of symptoms associated with an upper respiratory tract infection within the two weeks preceding surgery had a small but statistically significant increase in the incidence of intraoperative complications. These findings suggest that airway reactivity may be increased in the post-infection stage.

Similar findings were reported by McGill et al. ${ }^{1}$ who found a significant incidence of perioperative complications in a series of children who underwent tracheal intubation in the presence of a history of URI within one month prior to elective surgery. This also supports work by Empey ${ }^{5}$ who studied a group of adults and found that they had ranging degrees of altered respiratory tract reactivity for up to six weeks after an upper respiratory tract infection.

The mechanism by which this may occur is unclear. It is known that viral infections, particularly during the invasive phase, can cause morphological and functional changes of the respiratory epithelium. ${ }^{6,7}$ It may be that the epithelium in the period following the acute viral stage is in various stages of repair and that anaesthetic vapours administered at this time may penetrate areas of damaged epithelium and activate subepithelial irritant receptors, mast cells and smooth airway muscle, resulting in varying degrees of airway reactivity. The relationship between epithelial damage, anaesthesia, viral infections, and airway reactivity, however, remains unclear and to date no animal or human model has yet been developed to satisfactorily explain it. ${ }^{8}$

The potential for bias in this study lies principally in the selection of groups according to the presence or absence of respiratory symptoms. Since this study was performed concurrently with an ongoing prospective study involving the effect of anaesthesia on a select group of children who underwent myringotomy while harbouring acute uncomplicated URIs, ${ }^{9}$ documentation of respiratory symptoms and complications by the anaesthesia staff had been well established and were consistently documented. Of course, precise diagnosis of an URI is always difficult and this is particularly true when establishing a diagnosis retrospectively. It is certainly conceivable, therefore, that not all of the symptomatic children had true viral infections. Indeed, the overlap of URI symptoms with those of allergic actiology is frequently confounding. Unfortunately, we were unable to assess the numbers of patients cancelled due to severe URI symptoms and, therefore, the symptomatic group may have been somewhat preselected, with respect to severity.

The authors have, however, attempted to allocate patients to the symptomatic group based on the type of symptoms which have posed, by all previously defined criteria, an increased risk for intraoperative complications. In this respect, information from this study may be useful to the anaesthetist who must incorporate similar criteria in their evaluation of the patient for fitncss to undergo elective sùrgery.

This study suggests that anaesthesia in the presence of uncomplicated upper respiratory tract infections as defined by our criteria carries minimal associated morbidity and, under certain circumstances, may not be contraindicated. It would appear, however, from this retrospective study, that if the anaesthetist decides to postpone elective surgery due to the presence of an URI, the postponement should be for a period exceeding two weeks up to a month or longer.

Although there may be no substitute for clinical experience and acumen in deciding whether or not a patient is fit for anaesthesia and surgery while harbouring viral infections, it is hoped that these data may help to provide a scientific rather than empirical basis for decision-making,

\section{Acknowledgements}

The authors wish to thank Margo Douthat for preparation of the manuscript. 


\section{References}

1 McGill WA, Coveler LA, Epstein BS. Subacute upper respiratory infection in small children. Anesth Analg 1979; 58: 331 .

2 Koba BF, Jeon IS, Andre JM, Mackay I, Smith RM. Postintubation croup in children. Anesth Analg 1977; 56: 501.

3 Shope RE. The infection of ferrets with swine influenza virus. J Exper Med 1934; 60: 49

4 Dubin IN. The role of ether anesthesia in the production of influenza virus pneumonia in micc. J Immunol 1945; 51 : 355 .

5 Empey DW, Laitinen LA, Jacobs L, Gold WM, Nadel JA. Mechanisms of bronchial hyperreactivity in normal subjects after upper respiratory tract infection. Am Rev Respir Dis 1976; 113: 131 .

6 Hers $J F$. Disturbances of the ciliated epithelium due to influenza virus. Am Rev Respir Dis 1966; 93: 162.

7 Stuart-Harris CH. Respiratory viruses, ciliated epithelium, and bronchitis. Am Rev Respir Dis 1966; 93: 150.

8 Hirshman CA. Airway reactivity in humans. Anesthesiology 1983; $58: 170$.

9 Tait AR, Knight PR. Anesthesia and upper respiratory viral infections: a prospective cohort study. Anesthesiology 1985:63: A526.
Résumé

Une étude rétrospective de 3,585 patients dont l'age s'étend de la naissance à 20 ans a été entreprise afin d'investiguer la prévalence de complications respiratoires peropératoires chez les patients présentart des symptômes d'urte infection des voies aériennes respiratoires supérieures (URIs). II n'y avait aucune différence statistiquement significative concernant les complications étudiées entre les patients asymptomatiques (1.61 pour cent) el symptomatiques ( 1.64 pour cent). Cependant les patients asymptomatiques ayant eu une URI récente avaient un taux de complications significativement plus élevé $(5.31$ pour cent, $p<0.05$ ) que les patients asymptomatiques. Il n'y avait aucune différence significative dans les complicasions peropératoires entre les patients intubés ou non intubés. Il n'y avait aussi aucune association entre l'agent ancsthesique utilisé et la survenue des complications respiratoires peropératoires. Les résultats de celle étude suggèrent que les patients avec URI non compliqué ne présentent pas un risque élevé de complications. respiratoires peropératoires. Cependant les patients qui étaient asymptomatiques mais qui avajent une hisroire d'URI récente ont démontré une augmentation significative du risque d'apparition de complications peropératoires. 